THEORY AND METHODS

\title{
Neighbourhood deprivation and incidence of coronary heart disease: a multilevel study of 2.6 million women and men in Sweden
}

\author{
K Sundquist, M Malmström, S-E Johansson
}

J Epidemiol Community Health 2004;58:71-77

See end of article for authors' affiliations

Correspondence to:

Correspondence to:
Dr K Sundquist, Karolinska Institutet, Family Medicine Stockholm, Alfred Nobels allé 12, SE-14183 Huddinge, Sweden Kristina.Sundquist@ klinvet.ki.se

Accepted for publication 18 June 2003

\begin{abstract}
Study objective: To examine whether neighbourhood deprivation predicts incidence rates of coronary heart disease, beyond age and individual income.

Design: Follow up study from 31 December 1995 to 31 December 1999. Women and men were analysed separately with respect to incidence rates of coronary heart disease. Multilevel logistic regression was used in the analysis with individual level characteristics (age, individual income) at the first level and level of neighbourhood deprivation at the second level. Neighbourhood deprivation was measured at small area market statistics level by the use of Care Need Index.

Setting: Sweden.

Participants: All women and men aged 40-64 in the Swedish population, in total 2.6 million people.

Main results: There was a strong relation between level of neighbourhood deprivation and incidence rates of coronary heart disease for both women and men. In the full model, which took account of individual income, the risk of developing coronary heart disease was $87 \%$ higher for women and $42 \%$ higher for men in the most deprived neighbourhoods than in the most affluent neighbourhoods. For both women and men the variance at neighbourhood level was over twice the standard error, indicating significant differences in coronary heart disease risk between neighbourhoods.

Conclusions: High levels of neighbourhood deprivation independently predict coronary heart disease for both women and men. Both individual and neighbourhood level approaches are important in health care policies.
\end{abstract}

$\mathrm{S}$ ocioeconomic disparities in the risk of developing coronary heart disease (CHD), one of the major causes of death in Western countries, have been extensively examined in previous research. It has been shown that low individual social position (for example, low income) is strongly associated with both $\mathrm{CHD}^{1-5}$ and cardiovascular disease. $^{6-8}$ However, in recent research the role of the neighbourhood environment for our understanding of inequalities in health has received increased interest, ${ }^{9}$ and a number of international studies suggest that neighbourhood level characteristics may have an important influence on CHD risk. The neighbourhood level characteristics studied in conjunction with CHD include neighbourhood income, ${ }^{10}{ }^{11}$ neighbourhood education and occupational levels, ${ }^{12}{ }^{13}$ and neighbourhood segregation. ${ }^{14}$ Some of these studies have reported significant associations between neighbourhood level characteristics and CHD, beyond individual level characteristics. ${ }^{14} 15$

The notion that disease determinants are in part environmental was emphasised by Durkheim over a century ago when he stated that a population is more than only the sum of all individuals. ${ }^{16}$ This notion was developed in Rose's idea of the importance of distinguishing between the causes of individual cases of disease within a population, and the causes of differences in the rates of disease across populations. ${ }^{17}$ For example, if people within the same neighbourhood share the same socioeconomic environment, access to healthcare resources, norms settings and lifestyles, they may shape a common level of cardiovascular health beyond individual characteristics.

Even if these concepts are intriguing, it is only after the comparatively recent introduction of appropriate analytical methods (that is, multilevel regression models) ${ }^{18}$ that we are able to separate individual determinants of cardiovascular health from the effect of neighbourhood level characteristics. Hence, it has been possible to investigate how much of the individual differences in CHD risk can be attributed to the role of the neighbourhood socioeconomic characteristics beyond individual socioeconomic characteristics. ${ }^{15} 19$ Understanding these collective phenomena is relevant for both aetiological research and strategies of prevention. ${ }^{20}$ Previous studies of the neighbourhood effect on CHD risk have had some limitations such as lack of incidence data, small sample sizes, or an ecological design.

This multilevel study, therefore, analyses all Swedish women and men aged 40-64 years living in 8547 neighbourhoods with respect to CHD incidence, in total 2.6 million people. The Care Need Index (CNI), a composite deprivation index, measures neighbourhood deprivation.

The first aim of this study is to analyse whether there is an association between neighbourhood deprivation and incidence rates of CHD. The second aim is to analyse whether this association remains after accounting for individual income. The third aim is to analyse whether there is a neighbourhood effect on CHD beyond the individual effect.

\section{METHODS}

Study population and data sources

We performed a four year follow up study of the entire Swedish population aged 40-64 years, in total 2.6 million people. The participants were followed up from 31 December

Abbreviations: $\mathrm{CNI}$, Care Need Index; CHD, coronary heart disease; SAMS, small area market statistics 
1995 until first admission to hospital due to CHD or to censoring on 31 December 1999. All individual data were obtained from a national database including the whole Swedish population over 20 with annually collected individual information about, for example, sociodemographic characteristics and income. By means of a unique personal identification number we linked these data to the Cause of Death Register and the Swedish Hospital Discharge Register (National Board of Health and Welfare). All particpants were geocoded to their small area market statistics (SAMS) neighbourhoods. SAMS refers to the smallest administrative area units in Sweden with an average population of about 2000 residents in Stockholm and about 1000 residents in the rest of Sweden. The SAMS boundaries are drawn to include similar types of housing construction in a neighbourhood. Of the total 9667 SAMS existing in Sweden we excluded 1120 with less than 50 inhabitants because of unstable statistical estimates. This yielded a final sample of 8547 SAMS. A total of 64528 of the individuals $(2.8 \%)$ were excluded from the study because of missing SAMS codes. All 2.6 million individuals were divided into 10 groups (deciles) according to the level of neighbourhood deprivation in the SAMS neighbourhood where they lived. By this method each decile contained about one tenth of the individuals. The level of neighbourhood deprivation in each decile was calculated by the use of CNI.

\section{Neighbourhood level variable}

CNI: this index included proportions of seven socioeconomic and demographic items for each SAMS neighbourhood (that is, people with low educational status, unemployed people, elderly people living alone, children under age 5, single parents, residents who have moved house during the past year, and foreign born people from Finland, Southern and Eastern Europe, Asia, Africa, and South America), measured on 31 December 1995. CNI is an area based deprivation index aimed for distribution of primary healthcare resources. The different items in the CNI were originally constructed to measure the impact of these items on Swedish GPs' workload based on their own ranking, and the scale is constructed so that the higher the CNI score the more deprived the neighbourhood. ${ }^{21}$ The UPA score or under privileged area score has been used in the UK to allocate an extra deprivation payment to primary health care in the most deprived neighbourhoods and CNI is a Swedish adaptation of the UPA score. CNI was based on register data with individual information on the entire adult population. We chose CNI as a measure of neighbourhood deprivation, because it is accessible for all SAMS neighbourhoods in Sweden. Moreover, CNI is highly correlated to the Townsend score $(r=0.79)$, a deprivation index developed in the U.K. ${ }^{22}$ In previous studies, according to CNI, the most deprived neighbourhoods were associated with different health outcomes, including increased mortality rates. ${ }^{21} 2324$

\section{The steps in the calculation of the CNI}

(1) The seven items were expressed as proportions of total residents in each of the Swedish SAMS neighbourhoods.

(2) All Swedish GPs (response rate 64.8\%, 2000) ranked the impact on their workload of the seven items on a scale from 0-9, where a higher value implied a higher workload.

- Weight $_{\mathrm{i}}$

- Elderly living alone: 6.15

- Foreign born people: 5.72

- Unemployed people: 5.13
- Single parents: 4.19

- Residents who have moved: 4.19

- People with low educational status: 3.97

- Children under age 5: 3.23

(3) The population was then normalised by applying an angular transformation $(\operatorname{arc} \sin \sqrt{ })$, meaning that each item was transformed to a symmetrical distribution to minimise the disproportionate effect of outliners (extreme values). The means $\left(\mathrm{m}_{\mathrm{i}}\right)$ and standard deviations $\left(\mathrm{s}_{\mathrm{i}}\right)$ of the transformed proportions were calculated for Sweden as a whole.

For each SAMS CNI was calculated as follows: For each SAMS the proportions $\left(\mathrm{p}_{\mathrm{i}}\right)$ of the seven items were standardised by calculating $\mathrm{Z}$ scores (mean $=0$ and variance $=1$ ). For each item the deviation from Sweden was calculated. The standardised value for each item is calculated as follows:

$$
\mathrm{Zi}=\left[\left(\mathrm{p}_{\mathrm{i}}-\mathrm{m}_{\mathrm{i}}\right) / \mathrm{s}_{\mathrm{i}}\right]
$$

(4) The standardised value for each item $\left(Z_{i}\right)$ was multiplied by each weight ( weight $_{\mathrm{i}}$ ) calculated from the GPs' ranking. Thus the contribution of each item $\left(\mathrm{V}_{\mathrm{i}}\right)$ in $\mathrm{CNI}$ was calculated as follows:

$$
\mathrm{V}_{\mathrm{i}}=\text { weight }_{\mathrm{i}} \times \mathrm{Z}_{\mathrm{i}}
$$

For each SAMS the sum of $\mathrm{V}_{\mathrm{i}}$ for all the items in CNI was calculated to obtain the CNI value for every SAMS in Sweden:

$$
\mathrm{CNI}=\Sigma \mathrm{V}_{\mathrm{i}}
$$

(5) The mean value of CNI is 0 , which corresponds to the average value for Sweden as a whole. The higher the CNI value, the more deprived is the neighbourhood. The CNI values varies from-53 (most affluent) to +79 (most deprived).

\section{Individual level variables}

Age was used as a continuous variable, and centred at the mean age of all individuals.

Individual income was divided into quintiles according to income level.

As our sample included the whole population in the actual age group, individual data were limited to certain variables such as age, gender, and socioeconomic status (SES). We chose to use only income as a measure of SES as the correlation between different SES measures is high.

\section{Outcome variable}

Coronary heart disease was defined as first non-fatal admission to hospital according to WHO's International Classification of Diseases (ICD) version 9, codes 410-414, and ICD version 10, codes I20-I25. Persons with CHD hospitalisation during 1994 and 1995 were excluded. The validity of myocardial infarction diagnosis has been evaluated for 1987 and 1995 and was considered to be high. ${ }^{25}$

\section{Statistical analysis}

Age standardised incidence rates were calculated. We performed a multilevel logistic regression modelling, ${ }^{26}{ }^{27}$ with individuals at the first level and neighbourhoods at the second level, to estimate odds ratios with $95 \%$ CI. Because of the large sample size it was not possible to use a multilevel Cox proportional hazards model in the computing process. Therefore, we used a multilevel logistic regression instead without including time as a variable in the model. Under certain circumstances (large sample size, low outcome incidence rate, risk ratios of moderate size, and not too long follow up), logistic regression is a good approximation of 
Cox's proportional hazard model. ${ }^{28}$ We compared the two approaches by analysing a subsample of 25000 individuals with both a multilevel logistic regression and a multilevel Cox proportional hazards model, and the results were almost identical. Thus the results were presented as odds ratios (OR) as a good approximation of hazard ratios.

We performed three models with separate analyses for women and men. The full model included age, the neighbourhood variable, and individual income.

The logistic model used is given by:

$$
\mathrm{y}_{\mathrm{ij}}=\exp \left(\mathrm{f}_{\mathrm{ij}} \mathrm{u}_{\mathrm{j}} /\left(\mathrm{l}+\exp \left(\mathrm{f}_{\mathrm{ij}}+\mathrm{u}_{\mathrm{j}}\right)\right)+\mathrm{e}_{\mathrm{ij}}\right.
$$

where $f_{i j}$ denotes the fixed part of the model and $u_{j}$ the random part. The $\mathrm{e}_{\mathrm{ij}}$ denotes the residual part.

We calculated the second level (that is, neighbourhood) intercept variance.

We computed the intraclass correlation (ICC) — that is, the intra-neighbourhood correlation-in order to estimate to what extent the individual propensity for CHD for individuals within the same SAMS was similar compared with individuals in other SAMS areas. The ICC expresses the proportion of the total variance that is at the neighbourhood level. The ICC in multilevel logistic regression can be estimated by different procedures. ${ }^{29}$ We applied the latent variable method $^{26}$ as exemplified by:

$$
I C C=\frac{V_{n}}{V_{n}+\pi^{2} / 3}
$$

where $V_{n}$ is the between variance between neighbourhoods and $\pi^{2} / 3$ is the variance between individuals.

The proportion of the second level variance explained by the different variables was calculated as:

$$
V_{\text {EXPLAINED }}=\frac{V_{0}-V_{1}}{V_{0}} \times 100
$$

where $V_{\mathrm{o}}$ is the age adjusted variance in the initial model and $V_{1}$ is the second level variance in the different models

We tested whether there were any random effects by the two highest and the two lowest income levels. No such effects were found. This implies that the relation between the first level variables (individual income) and CHD was the same in all kinds of SAMS, independently of differences in individual income. Possible cross level interactions were tested, but none were found. We also examined whether there was any heterogeneity between the SAMS neighbourhoods in each CNI decile by calculating the variance for every decile. For example, for women, the highest variances were found in deciles 2, 6, 8, 9, and 10 .
Parameters were estimated by second order PQL. Extrabinomial variation was explored systematically in all models and we found no evidence of under or over dispersion. The MLwiN, Version 1.10.0007 software package ${ }^{30}$ was used to perform the analyses.

This study was approved by the ethical committee at Karolinska Institutet, Stockholm.

\section{RESULTS}

During the four years of follow up, 52360 people (14 259 women and 38101 men) developed CHD. Table 1 describes the sociodemographic characteristics of the population by CNI deciles and age adjusted CHD incidence rates. For both women and men CHD incidence rates increased with increasing neighbourhood deprivation. For women the incidence rate ratio in decile 10 (the most deprived decile), was twice as high as in decile 1 (the most affluent decile) while for men the rate ratio was 1.6.

Table 2A shows the age adjusted and full model for women. When individual income decreased and the level of neighbourhood deprivation increased, the risk of CHD increased. For example, in CNI decile 5 the risk of developing CHD was $29 \%$ higher $(\mathrm{OR}=1.29,95 \% \mathrm{CI}=1.18$ to 1.41 ) than in decile 1 . In decile 10 , representing the most deprived neighbourhoods, the CHD risk for women was $102 \%$ higher $(\mathrm{OR}=2.02,95 \% \mathrm{CI}=1.86$ to 2.20$)$ than in decile 1 , the most affluent neighbourhoods. This pattern remained in the full model after adjustment for age and individual income. In decile 5 the $\mathrm{CHD}$ risk was $23 \%$ higher $(\mathrm{OR}=1.23$, $95 \% \mathrm{CI}=1.13$ to 1.35$)$ and in decile 10 the CHD risk was $87 \%$ higher $(\mathrm{OR}=1.87,95 \% \mathrm{CI}=1.72$ to 2.03 ).

Table 2B shows the age adjusted and full model for men. In the age adjusted model the risk of developing CHD was 19\% higher $(\mathrm{OR}=1.19,95 \% \mathrm{CI}=1.13$ to 1.25$)$ in CNI decile 5 than in decile 1 . In decile 10 the CHD risk for men was $65 \%$ higher $(\mathrm{OR}=1.65,95 \% \mathrm{CI}=1.57$ to 1.73$)$ than in decile 1. In the full model this pattern remained. In decile 5 the risk of developing $\mathrm{CHD}$ was $10 \%$ higher $(\mathrm{OR}=1.10,95 \% \mathrm{CI}=1.04$ to 1.16 ) than in decile 1 and in decile 10 the CHD risk was $42 \%$ higher $(\mathrm{OR}=1.43,95 \% \mathrm{CI}=1.35$ to 1.49$)$ than in decile 1 .

The variance at neighbourhood level was over twice the standard error, indicating significant differences in CHD risk between neighbourhoods.

The ICC in the full model was 0.021 for women and 0.009 for men, indicating that $2.1 \%$ and $0.9 \%$ of the total variance could be explained at the neighbourhood level for women and men, respectively.

Table 1 Characteristics of the whole Swedish population aged 40 to 64 years, residing in 8547 neighbourhoods by neighbourhood Care Need Index (CNI), in deciles, and age standardised incidence rates of coronary heart disease, 1325284 men and 1312344 women, 31 December 1995 followed up until 31 December 1999

\begin{tabular}{llllll}
\hline & & & & \multicolumn{2}{l}{$\begin{array}{l}\text { Age standardised CHD incidence rates/10000 } \\
\text { person years }\end{array}$} \\
\cline { 5 - 6 } CNI in deciles & $\begin{array}{l}\text { Median* } \\
\text { income }\end{array}$ & Mean age & Men (\%) & Women & Men \\
\hline 1 (most affluent) & 16200 & 50.20 & 50.55 & 20 & 60 \\
2 & 15300 & 50.77 & 50.58 & 22 & 62 \\
3 & 14600 & 50.89 & 50.84 & 24 & 64 \\
4 & 14300 & 50.93 & 50.88 & 26 & 70 \\
5 & 14200 & 51.00 & 50.72 & 26 & 71 \\
6 & 14100 & 51.08 & 50.27 & 27 & 74 \\
7 & 13800 & 51.19 & 50.10 & 28 & 76 \\
8 & 13700 & 51.26 & 49.31 & 29 & 78 \\
9 & 13400 & 51.38 & 48.89 & 32 & 84 \\
10 (most & 12400 & 50.81 & 50.69 & 41 & 99 \\
deprived) & & & & \\
\hline \multirow{2}{*}{ *Annual individual income in euros. CHD, coronary heart disease. } &
\end{tabular}


Table 2 (A) Multilevel logistic regression showing odds ratios (and 95\% confidence intervals) of coronary heart disease by age, individual income, and deciles of Care Need Index (CNI) for the 1312344 women aged 40 to 64 years and residing in 8547 neighbourhoods, 31 December 1995 followed up until 31 December 1999

\begin{tabular}{|c|c|c|}
\hline Women & Age adjusted & Full model \\
\hline Individual characteristics & (age and income included) & (age, income, and CNI included) \\
\hline \multicolumn{3}{|l|}{ Median income* } \\
\hline 1st Quintile (highest income) & 1.00 (reference) & 1.00 (reference) \\
\hline 2nd Quintile & 1.24 (1.16 to 1.32$)$ & $1.22(1.14$ to 1.30$)$ \\
\hline 3rd Quintile & $1.47(1.38$ to 1.56$)$ & $1.46(1.37$ to 1.55$)$ \\
\hline 4th Quintile & $1.74(1.64$ to 1.85$)$ & $1.68(1.58$ to 1.78$)$ \\
\hline 5th Quintile (lowest income) & $1.75(1.65$ to 1.85$)$ & $1.70(1.60$ to 1.79$)$ \\
\hline Neighbourhood variance (SE) & $0.084(0.009)$ & See below \\
\hline Intraclass correlation (ICC) & 0.025 & See below \\
\hline Explained variance $(\%)$ & 16 & See below \\
\hline $\begin{array}{l}\text { Neighbourhood characteristics } \\
\mathrm{CNI} \text { in deciles }\end{array}$ & (age and $\mathrm{CNI}$ included) & \\
\hline 1 (most affluent) & 1.00 (reference) & 1.00 (reference) \\
\hline 2 & $1.00(0.92$ to 1.11$)$ & 1.07 (0.98 to 1.17$)$ \\
\hline 3 & $1.18(1.08$ to 1.29$)$ & $1.13(1.04$ to 1.24$)$ \\
\hline 4 & $1.33(1.22$ to 1.46$)$ & $1.28(1.17$ to 1.39$)$ \\
\hline 5 & $1.29(1.18$ to 1.41$)$ & 1.23 (1.13 to 1.35$)$ \\
\hline 6 & $1.38(1.26$ to 1.51$)$ & $1.33(1.21$ to 1.45$)$ \\
\hline 7 & 1.39 (1.27 to 1.52$)$ & $1.33(1.22$ to 1.45$)$ \\
\hline 8 & 1.45 (1.33 to 1.59$)$ & 1.39 (1.27 to 1.52$)$ \\
\hline 9 & $1.60(1.47$ to 1.75$)$ & $1.52(1.40$ to 1.66$)$ \\
\hline 10 (most deprived) & $2.02(1.86$ to 2.20$)$ & 1.87 (1.72 to 2.03$)$ \\
\hline Neighbourhood variance (SE) & $0.055(0.008)$ & $0.07(0.008)$ \\
\hline Intraclass correlation (ICC) & 0.016 & 0.021 \\
\hline Explained variance† (\%) & 45 & 30 \\
\hline
\end{tabular}

Individual income for women explained $16 \%$ of the age adjusted neighbourhood variance, and this percentage was $45 \%$ for the neighbourhood deprivation variable (CNI). For men the corresponding percentages were 35 and $44 \%$.

The full model including individual income and CNI explained 30 and $42 \%$ of the neighbourhood variance for women and men, respectively.

\section{DISCUSSION}

The main finding of this study is that neighbourhood deprivation, measured with CNI, predicts CHD incidence rates for both women and men. This association remains after adjustment for individual income. Furthermore, there is a neighbourhood effect on CHD beyond the individual effect.

Table 2 (B) Multilevel logistic regression showing odds ratios (and 95\% confidence intervals) of coronary heart disease by age, individual income, and deciles of Care Need Index (CNI) for the 1325284 men aged 40 to 64 years and residing in 8547 neighbourhoods 31 December 1995, followed up until 31 December 1999

\begin{tabular}{|c|c|c|}
\hline Men & Age adjusted & Full model \\
\hline $\begin{array}{l}\text { Individual characteristics } \\
\text { Median income* }\end{array}$ & (age and income included) & (age, income and $\mathrm{CNI}$ included) \\
\hline 1st Quintile (highest income) & 1.00 (reference) & 1.00 (reference) \\
\hline 2nd Quintile & 1.24 (1.19 to 1.28$)$ & $1.21(1.17$ to 1.26$)$ \\
\hline 3rd Quintile & 1.40 (1.35 to 1.45$)$ & $1.36(1.31$ to 1.40$)$ \\
\hline 4th Quintile & $1.57(1.51$ to 1.62$)$ & $1.50(1.45$ to 1.55$)$ \\
\hline 5th Quintile (lowest income) & 1.71 (1.65 to 1.77$)$ & $1.62(1.56$ to 1.68$)$ \\
\hline Neighbourhood variance (SE) & $0.034(0.004)$ & See below \\
\hline Intraclass correlation (ICC) & 0.010 & See below \\
\hline Explained variance $(\%)$ & 35 & See below \\
\hline $\begin{array}{l}\text { Neighbourhood characteristics } \\
\mathrm{CNI} \text { in deciles }\end{array}$ & (age and CNI included) & \\
\hline 1 (most affluent) & 1.00 (reference) & 1.00 (reference) \\
\hline 2 & $1.04(0.99$ to 1.10$)$ & 1.01 (0.96 to 1.07$)$ \\
\hline 3 & $1.08(1.03$ to 1.14$)$ & $1.02(0.97$ to 1.08$)$ \\
\hline 4 & $1.18(1.12$ to 1.25$)$ & $1.10(1.04$ to 1.16$)$ \\
\hline 5 & $1.19(1.13$ to 1.25$)$ & $1.10(1.04$ to 1.16$)$ \\
\hline 6 & $1.25(1.18$ to 1.31$)$ & $1.15(1.09$ to 1.21$)$ \\
\hline 7 & $1.28(1.21$ to 1.34$)$ & $1.16(1.10$ to 1.23$)$ \\
\hline 8 & 1.34 (1.28 to 1.42$)$ & $1.19(1.13$ to 1.25$)$ \\
\hline 9 & $1.40(1.33$ to 1.48$)$ & $1.26(1.20$ to 1.33$)$ \\
\hline 10 (most deprived) & 1.65 (1.57 to 1.73$)$ & $1.42(1.35$ to 1.49$)$ \\
\hline Neighbourhood variance (SE) & $0.029(0.003)$ & $0.03(0.003)$ \\
\hline Intraclass correlation (ICC) & 0.009 & 0.009 \\
\hline Explained variance† (\%) & $44 \%$ & $42 \%$ \\
\hline
\end{tabular}




\section{Key points}

- Neighbourhood deprivation, measured with the Care Need Index, predicts incidence rates of coronary heart disease for both women and men, after taken individual income into account.

- There is a neighbourhood effect on coronary heart disease, for both women and men, beyond the individual effect.

- Strategies of coronary heart disease prevention need to combine individual level approaches with neighbourhood level approaches.

Based on the whole middle aged population of Sweden, this study confirms that low individual income and high levels of neighbourhood deprivation increase the individual's risk of developing CHD. ${ }^{8}{ }^{15} 20$ In addition, our study adds further evidence to the postulate that neighbourhood characteristics are an important predictor of CHD beyond the individual characteristics. Therefore, both a neighbourhood perspective and an individual perspective are needed when studying socioeconomic factors and their relation with individual CHD risk.

In agreement with this study, a large body of research in Europe and the USA has shown a strong relation between low individual SES and CHD. ${ }^{131}$ In the UK, civil servants with the lowest compared with the highest employment grade participating in the 25 year Whitehall follow up study had a 1.56 times increased risk of CHD. ${ }^{3}$ Longitudinal Finnish data revealed even higher $\mathrm{CHD}$ mortality and morbidity rates among men and women with low SES. ${ }^{4}$ The Scottish heart health study, in which both an area based deprivation indicator and the individual social position were used, showed an association with CHD. ${ }^{32}$ To study the effect of neighbourhood level characteristics on CHD outcomes, independent of individual level characteristics, some previous studies have used multilevel models. Our study agreed with these studies, ${ }^{14}{ }^{15}$ demonstrating an independent effect of neighbourhood deprivation on incidence rates of CHD. In contrast, other studies disagreed with our study and suggested that the differences in CHD risk between neighbourhoods are merely a result of differences between individuals. ${ }^{33-35}$ However, our multilevel study included the entire middle aged Swedish population and showed a significant variance between neighbourhoods, implying that there were significant differences in CHD risk between neighbourhoods.

Various mechanisms in the causal pathway between the neighbourhood effects on individual health have been suggested. It is possible that living in deprived neighbourhoods implies isolation from people with healthy behaviours for the heart. Such behaviour includes a healthy diet, physical activity, and non-smoking and might act as a mediator between living in deprived neighbourhoods and increased CHD risk. However, in a multilevel study from the US, mortality risks were higher in deprived neighbourhoods even after adjustment for individual body mass index and smoking. ${ }^{36}$ Another multilevel study from the US demonstrated the importance of income inequality for mortality.$^{37}$ In contrast with the US, Canada has a lower degree of income inequality and in Nova Scotia, Canada, neighbourhood socioeconomic characteristics were not significantly associated with mortality. ${ }^{38}$ In the UK, previous studies of places and people have shown a neighbourhood effect on health, and Macintyre ${ }^{39}{ }^{40}$ suggests a theoretical framework with five

\section{Policy implications}

- Individual level approaches should be combined with neighbourhood level approaches to reduce socioeconomic disparities in the risk of developing coronary heart disease. For clinicians in deprived neighbourhoods it is important to consider both individual and neighbourhood socioeconomic characteristics in the treatment and prevention of CHD. Moreover, when planning the distribution of healthcare resources it is of great importance to consider the level of neighbourhood deprivation, as measured with the Care Need Index, to better reach people who are at high risk of developing CHD.

types of features of neighbourhoods that might explain differences in health: (1) physical features of the environment shared by all residents in a locality, (2) availability of healthy environments at home, work, and play; (3) services provided, publicly or privately, to support people in their daily lives; (4) socio-cultural features of a neighbourhood; and (5) the reputation of an area. All these features are probably closely related to the level of neighbourhood deprivation and the risk of developing CHD.

Living in deprived neighbourhoods also means isolation from health promoting milieus, for example, safe places to exercise, decent housing, and services provided. The experience of being discriminated against in deprived neighbourhoods with a poor reputation may also contribute to a negative cardiovascular health profile, which may be especially important for women. ${ }^{41}$

In comparisons of wealthy nations, the association between neighbourhood characteristics and different health outcomes was inconsistent. ${ }^{42}$ For example, France, Italy, and Spain, countries with higher income inequalities, had higher life expectancy than Denmark and Finland, countries with lower income inequality. This implies that neighbourhood characteristics as determinants of health are of a complex nature and might also include evenly distributed access to health care, education, and social services. This evenness is absent in the US, where the effects of income inequalities on health are more pronounced.

Sweden is a society well known for its equity. However, we found a significant neighbourhood effect, as measured with CNI, on CHD risk. Several plausible pathways might generate these neighbourhood differences in health, including physical and psychosocial features of the environment, housing, services provided, isolation from health promoting milieus, and discrimination. It is also possible that relative poverty is of greater importance than absolute poverty in a wealthy nation like Sweden. Historical and cultural features of a country are also important to consider, especially if comparisons between countries are desirable.

We want to emphasise that if aspects of the social environment influence health by operating as upstream determinants of individual characteristics, ${ }^{9}$ then control for many downstream individual characteristics may over-adjust the true effects of the context. ${ }^{43}$ This is even more salient if one poses the cross level casual question in a life course developmental framework, where the effects of various aspects of the environment are literally embodied over time ${ }^{44-46}$ so that what is assigned as an individual level variable at one time point could equally be conceptualised as a characteristic of past environments in which those individuals grew up. 


\section{Strengths and limitations}

This study has several strengths. Firstly, the Swedish Population Register is highly complete with very few missing data. For example, data about income were quite complete $(99.4 \%)$. Completeness of addresses for geocoding to determine area based location was also high, and only $2.4 \%$ of the individuals were excluded because of missing SAMS codes. The use of a personal identification number makes it possible to follow individuals in different registers, for example, the migrant register, permitting calculation of exact risk time. Secondly, the validity of the In-Care Register concerning the diagnosis myocardial infarction has been evaluated and is of high quality. ${ }^{25}$ Thirdly, the prospective nature of our data allowed us to calculate incidence rates of CHD, rather than prevalence, a much stronger outcome for determining causal relations. Fourthly, data consisted of the entire Swedish population, women and men, aged 40-64. Fifthly, our area based measure, CNI, included proportions of seven socioeconomic and demographic items for each SAMS neighbourhood. Earlier studies of CNI have shown a strong association between CNI and other health outcomes..$^{21} 2324$ Finally, the use of multilevel modelling helped us to separate the neighbourhood effect from the individual effect on CHD risk, considering both fixed and random effects in the analyses. ${ }^{47}$

Our study also has some limitations. Firstly, we had no information on individual level risk factors for CHD (for example, smoking, diet, and physical activity). However, risk factors could be considered as mediators in the causal pathway between neighbourhoods and CHD, rather than confounders. Secondly, we were not able to adjust the models for the length of time participants had lived in their neighbourhoods (that is, exposure). However, in a Swedish survey conducted by Statistics Sweden 1986-1993, it was found that $75 \%$ had lived at their home address for at least eight years preceding the survey. Thirdly, the selection of SAMS neighbourhoods might imply selection bias, but in this study almost all SAMS neighbourhoods in Sweden were included. Although it is possible that SAMS is not the best proxy for defining the "true social boundaries" that may influence CHD risk, SAMS seems coherent when it comes to both ownership and the type of buildings that make up the area. Therefore, this level may represent a rather natural delimitation of the social environment. Fourthly, in studies of the neighbourhood effect on health, selective residential mobility (deprived individuals move to deprived neighbourhoods) is part of the process that drives compositional neighbourhood differences. However, we adjusted for individual income, allowing us to differentiate between the compositional and contextual effect on CHD risk. However, we cannot rule out the possibility that the observed association between neighbourhood deprivation and CHD risk is the result of residual individual confounding by unobserved socioeconomic characteristics. ${ }^{48}$ For example, individual education and income cannot be measured precisely. ${ }^{49} 50$

\section{ACKNOWLEDGEMENTS}

The authors wish to thank Helena Ahlén at Karolinska Institutet, Family Medicine Stockholm, for statistical analyses, and Sanna Sundquist, student at Foothill College, California, for technical assistance.

\section{Authors' affiliations \\ K Sundquist, M Malmström, S-E Johansson, Karolinska Institutet, Family Medicine, Stockholm, Sweden}

Funding: this work was supported by grants from the National Institutes of Health (1 RO1 HL71084-01), the Swedish Council for Working Life and Social Research (2001-2373), the Swedish Research Council
(K2001-27X-1 1651-06C), the Knut and Alice Wallenberg Foundation, and the Stockholm County Council.

Conflicts of interest: none declared.

\section{REFERENCES}

1 Bucher HC, Ragland DR. Socioeconomic indicators and mortality from coronary heart disease and cancer: a 22-year follow-up of middle-aged men. Am J Public Health 1995;85:1231-6.

2 Kunst AE, Groenhof F, Andersen O, et al. Occupational class and ischemic heart disease mortality in the United States and 11 European countries. Am J Public Health 1999;89:47-53.

3 Hemingway H, Shipley M, Macfarlane P, et al. Impact of socioeconomic status on coronary mortality in people with symptoms, electrocardiographic abnormalities, both or neither: the original Whitehall study 25 year follow up. J Epidemiol Community Health 2000;54:510-16.

4 Salomaa V, Niemela M, Miettinen $\mathrm{H}$, et al. Relationship of socioeconomic status to the incidence and prehospital, 28-day, and 1-year mortality rates of acute coronary events in the FINMONICA myocardial infarction register study. Circulation 2000;101:1913-18.

5 Wamala SP. [Large social inequalities behind women's risk of coronary disease. Unskilled work and family strains are crucial factors]. Lakartidningen 2001;98:177-81

6 Lynch JW, Kaplan GA. Socioeconomic position. In: Berkman LF, Kawachi I, eds. Social epidemiology. New York: Oxford University Press, 2000:13-35.

7 Marmot M. Multilevel approaches to understanding social determinants. In: Berkman LF, Kawachi I, eds. Social epidemiology. New York: Oxford University Press, 2002:349-67.

8 Kaplan GA, Keil JE. Socioeconomic factors and cardiovascular disease: a review of the literature. Circulation 1993;88:1973-98.

9 Kaplan GA. What is the role of the social environment in understanding inequalities in health? Ann N Y Acad Sci 1999:896:116-19.

10 Wing S, Casper M, Riggan W, et al. Socioenvironmental characteristics associated with the onset of decline of ischemic heart disease mortality in the United States. Am J Public Health 1988;78:923-6.

11 Mackenbach JP, Looman CW, Kunst AE. Geographic variation in the onset of decline of male ischemic heart disease mortality in The Netherlands. Am J Public Health 1989;79:1621-7.

12 Wing S, Barnett E, Casper M, et al. Geographic and socioeconomic variation in the onset of decline of coronary heart disease mortality in white women. Am J Public Health 1992;82:204-9.

13 Armstrong D, Barnett E, Casper M, et al. Community occupational structure, medical and economic resources, and coronary mortality among US blacks and whites, 1980-1988. Ann Epidemiol 1998;8:184-91.

14 LeClere FB, Rogers RG, Peters K. Neighborhood social context and racial differences in women's heart disease mortality. J Health Soc Behav 1998;39:91-107.

15 Diez-Roux AV, Nieto FJ, Muntaner C, et al. Neighborhood environments and coronary heart disease: a multilevel analysis. Am J Epidemiol 1997; 146:48-63.

16 Durkheim E. The rules of sociological method [Originally published in 1895]. [Luke S, ed] New York: Free Press, 1982.

17 Rose GA. Individuals and populations. The strategy of preventive medicine. Oxford: Oxford University Press, 1992.

18 Goldstein H. Multilevel statistical models, 3rd edn. London: Hodder Arnold, 2003.

19 Kolegard Stjarne M, Diderichsen F, Reuterwall C, et al. Socioeconomic context in area of living and risk of myocardial infarction: results from Stockholm Heart Epidemiology Program (SHEEP). J Epidemiol Community Health 2002;56:29-35.

20 Diez Roux AV, Merkin SS, Arnett D, et al. Neighborhood of residence and incidence of coronary heart disease. N Engl J Med 2001;345:99-106.

21 Malmstrom M, Sundquist J, Johansson SE, et al. The influence of social deprivation as measured by the CNI on psychiatric admissions. Scand J Public Health 1999;27:189-95.

22 Malmstrom M, Sundquist J, Bajekal M, et al. Indices of need and social deprivation for primary health care. Scand J Soc Med 1998;26:124-30.

23 Sundquist J, Malmstrom M, Johansson SE. Cardiovascular risk factors and the neighbourhood environment: a multilevel analysis. Int J Epidemiol 1999;28:841-5.

24 Malmstrom $M$, Sundquist J, Bajekal M, et al. Ten-year trends in all-cause mortality and coronary heart disease mortality in socio-economically diverse neighbourhoods. Public Health 1999;1 13:279-84.

25 The National Board of Health and Welfare. Värdering av diagnoskvaliteten för akut hiärtinfarkt i patientregistret 1987 och 1995 [In Swedish]. Stocknolm: Epidemiologiskt Centrum, Socialstyrelsen, 2000. (http://www.sos.se/epc/ pdf/rapp8795.pdf)

26 Snijders TAB, Bosker RJ. Multilevel analysis: an introduction to basic and advanced multilevel modeling. Thousand Oaks, CA: Sage, 1999.

27 Larsen K, Petersen JH, Budtz-Jorgensen E, et al. Interpreting parameters in the logistic regression model with random effects. Biometrics 2000;56:909-14.

28 Callas PW, Pastides H, Hosmer DW. Empirical comparisons of proportional hazards, poisson, and logistic regression modeling of occupational cohort data. Am J Ind Med 1998;33:33-47.

29 Goldstein H, Browne W, Rasbash J. Partitioning variation in multilevel models. http://www.ioe.ac.uk/hgpersonal/Variance-partitioning.pdf

30 Rasbash J, Browne W, Goldstein H, et al. A user's guide to MLwiN. version $2.1 \mathrm{ed}$. London: Multilevel Models Project, Institute of Education, University of London, 2000. 
31 Pappas G, Queen S, Hadden W, et al. The increasing disparity in mortality between socioeconomic groups in the United States, 1960 and 1986. N Engl J Med 1993;329:103-9.

32 Woodward M. Small area statistics as markers for personal social status in the Scottish heart health study. J Epidemiol Community Health 1996;50:570-6.

33 Sloggett A, Joshi H. Higher mortality in deprived areas: community or personal disadvantage? BMJ 1994;309:1470-4.

34 Sloggett A, Joshi H. Deprivation indicators as predictors of life events 19811992 based on the UK ONS longitudinal study. J Epidemiol Community Health 1998;52:228-33.

35 Osler M, Prescott E, Gronbaek M, et al. Income inequality, individual income, and mortality in Danish adults: analysis of pooled data from two cohort studies. BMJ 2002;324:13-16.

36 Yen IH, Kaplan GA. Neighborhood social environment and risk of death: multilevel evidence from the Alameda County Study. Am J Epidemiol 1999; 149:898-907.

37 Lochner K, Pamuk E, Makuc D, et al. State-level income inequality and individual mortality risk: a prospective, multilevel study. Am J Public Health 2001;91:385-91.

38 Veugelers PJ, Yip AM, Kephart G. Proximate and contextual socioeconomic determinants of mortality: multilevel approaches in a setting with universal health care coverage. Am J Epidemiol 2001;154:725-32.

39 Macintyre S, Ellaway A. Ecological approaches: rediscovering the role of the physical and social environment. In: Berkman LF, Kawachi I, eds. Social epidemiology. New York: Oxford University Press, 2000:332-48.

40 Macintyre S, Maciver S, Sooman A. Area, class and health: should we be focusing on places or people? J Soc Policy 1993;22:213-34.
41 Fleury J, Keller C, Murdaugh C. Social and contextual etiology of coronary heart disease in women. J Womens Health Gend Based Med 2000;9:967-78.

42 Lynch J, Davey Smith G, Hillemeier M, et al. Income inequality, the psychosocial environment, and health: comparisons of wealthy nations. Lancet 2001;358:194-200.

43 Diez-Roux AV. Multilevel analysis in public health research. Annu Rev Public Health 2000;21:171-92.

44 Davey Smith G, Gunnell D, Ben-Schlomo Y. Lifecourse approaches to socioeconomic differentials in cause-specific adult mortality. In: Leon D Walt G, eds. Poverty, inequality and health. Oxford: Oxford University Press, 2000.

45 Krieger $\mathbf{N}$. Theories for social epidemiology in the 21 st century: an ecosocial perspective. Int J Epidemiol 2001;30:668-77.

46 Morenoff J, Lynch JW. What makes a place healthy? Neighbourhood influences on racial/ethnic disparities in health over the life course. National Academy of Science, Health Disparities and Aging symposium, Washington, DC, March 2002

47 Merlo J. Multilevel analytical approaches in social epidemiology: measures of health variation compared with traditional measures of association. $J$ Epidemiol Community Health 2003;57:550-2.

48 Hart C, Ecob R, Davey Smith G. People, places and coronary heart disease risk factors: a multilevel analysis of the Scottish heart health study archive. Soc Sci Med 1997:45:893-902

49 Kaufman JS, Cooper RS, McGee DL. Socioeconomic status and health in blacks and whites: The problem of residual confounding and the resiliency of race. Epidemiology 1997;8:621-8.

50 Braveman P, Cubbin C, Marchi K, et al. Measuring socioeconomic status/ position in studies of racial/ethnic disparities: maternal and infant health. Public Health Rep 2001; 116:449-63.

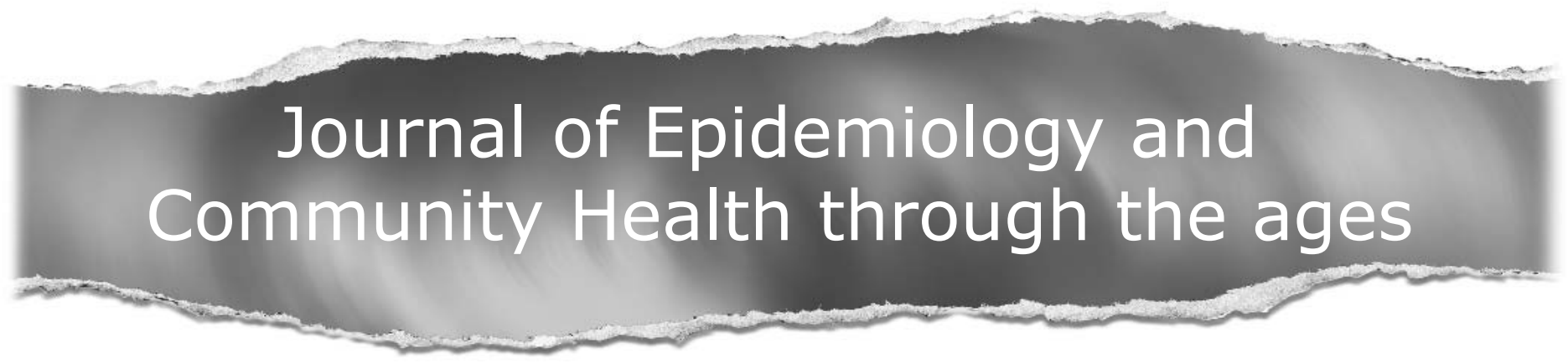

\section{Browse the Archive}

Journal of Epidemiology and Community Health online has an archive of content dating back to 1978.

Full text from January 2000; abstracts from 1978; table of contents from 1978

www.jech.com 


\section{LETTER}

If you have a burning desire to respond to a paper published in JECH, why not make use of our "rapid response" option?

Log on to our web site (www.jech.com), find the paper that interests you, and send your response via email by clicking on the "eletters" option in the box at the top right hand corner.

Providing it isn't libellous or obscene, it will be posted within seven days. You can retrieve it by clicking on "read eletters" on our homepage.

The editors will decide as before whether to also publish it in a future paper issue.

\section{Bullying, workers' health, and labour instability}

Violence and bullying in the workplace seem to be an increasing phenomenon in Europe, even though self reported bullying shows wide variations across nations. ${ }^{1}$ Bullying in the workplace is certainly not a recent phenomenon and is probably inherent to many human relations and organisations. However, its rising importance could be related to the global deterioration of working conditions. ${ }^{12}$ Thus the European Parliament, besides an increasing number of countries has legislated to cut down on and prevent these occurrences. ${ }^{4}$

Notwithstanding the importance of these legal measures, we are faced with crucial problems. At the working population level, the crux of the matter is that we are facing two unresolved questions: how can we measure bullying behaviours and its deleterious effects on the victim? What are the dimensions of interest? Which methods can be used? The wide variations observed across surveys and/or places is probably the expression of the difficulty in measuring bullying, and moreover, of the different interpretations from one context to another one. The second question is what impact has bullying on the worker's health and wellbeing?

According to Einarsen, bullying is characterised by "repeated and enduring negative acts"..$^{5}$ Its manifestations are described in the literature as forms of "intimidation", "physical violence", "discrimination", "threats",

\section{Key points}

- Bullying in the workplace seems to be an increasing phenomenon in Belgium

- In this survey bullying is a significant independent predictor of sick leave

- More research is needed to validate instruments that measure bullying

- Research is needed to evaluate the effects of the new legislation

- More should be done at the workplace level to prevent it "social isolation", "destabilisation". As Hirigoyen states, bullying can be behaviours, words, acts, gestures, writings that can affect the personality, the dignity, or physical or psychological integrity. ${ }^{6}$

We conducted a longitudinal survey in Belgium (two measures, one year interval) on psychosocial factors at work and their influence on the worker's health. ${ }^{7}$ With the working hypothesis that bullying, as other stressors, could have a negative impact on health. A second hypothesis was that in an unstable work environment, besides being exposed to higher stress, bullying could be an additional stressor.

The objective was double: to assess the bullying prevalence-including its comparison in different work environments-and to study its eventual negative effects on the victims.

Bullying is one of the negative environmental characteristics in the workplace that can have an impact on the worker's health; we measured it through a self administered postal questionnaire submitted to all workers in two enterprises (one stable and one unstable). Work instability is understood as enterprise instability-that is, recent or future merge, downsizing, or restructuring. The two workplaces are from the tertiary sector (service industry). The asset of such design survey is the possibility to study bullying on large samples and to go beyond individual case report, which is often the case in this subject matter. Another advantage is the longitudinal protocol, which permits more interpretations than cross sectional design.

Identical questionnaires were sent to all workers twice: in 2000 and in 2001. Global participation (completed questionnaires) was about $40 \%$, and 1030 workers (two thirds women) participated to the two measures; 549 in the stable enterprise, 481 in the unstable one. Participants were representative of the total worker's population for the available criteria: age, sex, department/service. Two among the five dimensions of Quine's instrument were used to measure bullying at work: namely isolation and destabilisation. ${ }^{8}$ The upper quartile of a score based on all those seven items defined arbitrarily the category of "presently bullied". Self reported repeated absenteeism was used as health indicator, defined as at least three sick leaves between the two measures.

In the unstable work environment, there is a significant increase in the proportion of bullied workers between the two measures (from $27 \%$ to $33 \%, p<0.05 \%$, Mc Nemar test for paired samples). The two most often cited items of bullying are "a constant undervaluing of my efforts" and "withholding necessary information".

Repeated absenteeism remains stable in the two firms, but its prevalence is higher in the unstable firm, for the two measures (around $11 \%$ in the stable, $16 \%$ in the unstable one).

Cross sectional data (at the first measure and at the second one) show very important relations between bullying and different health outcomes (subjective health status, depression, anxiety, somatisation, neuroticism, or chronic fatigue). Bullied workers being always at higher risk of the mentioned health problems than non-bullied ones. No noticeable differences could be observed in terms of gender, nationality, education, professional qualification, or health related behaviours (smoking, alcohol consumption, and alcohol dependence).

Prospective data analysis permits a better comprehension of the pathways and relations between risk factors and health outcomes. We have conducted logistic regressions on these prospective data (paired samples; each of the 1030 participant workers answered twice to the same questionnaire, in a one year interval). The goodness of fit of the model was tested with the Homer and Lemeshow test.

After having controlled for sex, age, education, work instability, and two stress models-that is, the Karasek' job demands control-social support (JDC-S) and the Siegrist' efforts rewards imbalance (ERI) models, ${ }^{10}$ we found significant relations between bullying (measured at the first point) and repeated absenteeism (measured at the second point, one year later). Bullied workers have a double risk of repeated absences than non-bullied ones (OR:2.3; $95 \%$ CI 1.4 to 4.0 ). We can therefore conclude that repeated absenteeism and bullying are more frequent in an unstable work environment, as we can also observe that bullied workers have a much higher risk of absenteeism than the others.

Undoubtedly, self reported measure of bullying and of health outcomes are subject to limitation and the validation of the first could be questioned. Other methodologies, like in depth interviews or focus groups could launch other figures and information. However, few studies have investigated this new psychosocial dimension in large scale populations of workers, and to our knowledge, none in Belgium. However, some studies like the ones of Kivimäki et al or Voss et al-even though they show large discrepancies in the bullying prevalencehave also found clear relations between workplace bullying and absenteeism. ${ }^{11}$

It is essential to denounce bullying, which has negative consequences not only for the workers but also at the managerial level: absenteeism, turn over, loss of productivity. The consideration of this practice is not to be placed at the individual level only, but can be considered as a collective nuisance, and, in some cases, as a workplace strategy directed to individuals.

Further researches are crucial to explore and validate the methodological aspects of bullying measurement as well as the influences of bullying on different health outcomes by way of well conducted prospective epidemiological studies. It is also too early to evaluate the effects of the new regulation on the prevention of bullying. Explanations and prevention could be sought in a more global, organisational, and economic environment to prevent this from happening, and not at the individual level solely, even if victims must be helped and supported. Unstable, fragile workplaces-nowadays such a common reality for so many workers-deserve special attention. 
I M Godin

School of Public Health, Universite Libre de Bruxelles, CP 596808 Route de Lennik, Brussels 1070, Belgium; igodin@ulb.ac.be

Funding: this study is supported by the Federal Office for Scientific, Technical and Cultural Affairs, Belgium.

\section{References}

1 Paoli P, Merllié D. Third European survey on working conditions 2000. Dublin: European Foundation for the Improvement of Living and Working Conditions, 2001.

2 Ferrie J, Marmot M, Griffiths J, Ziglio E, eds. Labour market changes and job insecurity: a challenge for social welfare and health promotion. Denmark: WHO Regional Publications, 1999.

3 European Parliament. Health and safety at work Council Directive 89/391/EEC on the introduction of measures to encourage improvements in the safety and health of workers at work: OJ L 183, 29.6.1989. 89/391/CEE. 209-2001.

4 Perimäki-Dietrich R. Violence at the workplace. TUTB Newsletter 2002;19-20:20-2.

5 Einarsen S. Harassment and bullying at work; a review of the Scandinavian approach Aggression and Violent Behavior 2000;5:379-401.

6 Hirigoyen M-F. Le harcèlement moral. La violence perverse au quotidien. Paris: La Découverte et Syros, 1998.

7 Siegrist J, Starke D, Chandola T, et al. Measurement of effort-reward imbalance at work: European comparisons. Soc Sci Med (in press).

8 Quine L. Workplace bullying in NHS community trust: staff questionnaire survey. BMJ 1999:318:228-32.

9 Karasek R. Job demands, job decision latitude, and mental strain: implications for job redesign. Administrative Science Quarterly 1979;24:285-308.

10 Siegrist J. Adverse health effects of high effort low reward conditions at work. Journal of Occupational Health Psychology 1996;1:27-43.

11 Voss M, Floderus B, Diderichsen F. Physical psychosocial, and organisational factors relative to sickness absence: a study based on Sweden Post. Occupational and Environmental Medicine 2001;58:178-84.
12 Kivimäki M, Elovainio M, Vahtera J. Workplace bullying and sickness absence in hospital staff. Occupational and Environmental Medicine 2000;57:656-60.

\section{BOOK REVIEW}

Tackling health inequalities since the Acheson Inquiry

E Exworthy, M Stuart, D Blane, M Marmot. (Pp 68; £ 14.95). The Policy Press, Bristol, 2003. ISBN 1-86134-504-6

A decade ago, the then British government shunned the very mention of the phrase "health inequalities". Its successor, by contrast, began by commissioning the Acheson Inquiry (1998) and has since introduced a large number of policy initiatives across a number of government departments to reduce health inequalities. This useful book reviews in detail how three areas of policy highlighted by Acheson have been implemented so far (tax and benefit reform performance management, and transport).

It is a short book that nevertheless touches on some large themes. To take an example: it is easier for governments to target identifiable deprived neighbourhoods than to target deprived people, many of whom live in affluent or middle income areas. The book acknowledges that such an approach to health inequalities is likely to fail in the long run (and that governments are more concerned with the short run).

Similarly, the authors show how the government's approach seems to be based on economics rather than social justice: poor health is a poor use of human resources, and policies focus on employment and the future workforce (children) rather than, say, the quality of life of older people. The authors might have been more explicit about the government's failure to promote policies such as progressive taxation and improving public transport.
The book will not cheer those who wish to see government policies evidence based. Robust evidence for the effectiveness of many of the policies is missing (an absence somewhat glossed over in the Acheson report), while the sheer number of initiatives means that the effectiveness of any one of them will be impossible to evaluate. It will not be possible to assess whether the policies as an aggregate have reduced health inequalities for some years to come. Inevitably, therefore, this book's early intelligence is both very welcome and rather tantalising.

S Abbott

\section{CORRECTION}

doi: 10.1136/jech.2003.009506corrl

An authors' error occurred in this paper by Dr Sundquist and others (2004;58:71-7).

Page 71 , left column, second paragraph, line 8, a reference should be inserted Merlo J, Lynch J W, Yang M, et al. Effect of neighborhood social participation on individual use of hormone replacement therapy and antihypertensive medication: a multilevel analysis. Am J Epidemiol 2003;157:774-83. Page 71, right column, first paragraph, line 8, exchange the existing reference (20) with reference Merlo J, Asplund K, Lynch J, et al. Population effects on individual systolic blood pressure-a multilevel analysis of WHO MONICA project. 43rd Annual conference on cardiovascular disease epidemiology and prevention in association with the council on nutrition, physical activity and metabolism, 2002. Page 75, right column, last paragraph, lines 5 and 12, a reference should be inserted Merlo J, Lynch JW, Yang M, et al. Effect of neighborhood social participation on individual use of hormone replacement therapy and antihypertensive medication: a multilevel analysis. Am J Epidemiol 2003;157:77483. 